\title{
Codificação com a Classificação Internacional de Cuidados Primários (ICPC) por internos de Medicina Geral e Familiar
}

Daniel Pinto,* Susana Corte-Real**

\section{RESUMO}

Objectivos: Determinar a capacidade de médicos na segunda metade do internato em Medicina Geral e Familiar em Portugal para codificar com a Classificação Internacional de Cuidados Primários - segunda edição (ICPC-2).

Tipo de estudo: Transversal, analítico.

Local: Zonal Sul de Portugal Continental, Açores e Madeira.

População: Médicos internos dos 29. e 30. cursos da Coordenação de Internato de Medicina Geral e Familiar da Zona Sul.

Métodos: Uma amostra de conveniência de 100 internos foi contactada por correio electrónico, sendo-lhes pedido que codificassem as descrições de três consultas elaboradas pelos autores. A codificação correcta dos motivos de consulta, problemas e procedimentos foi determinada pelos autores em colaboração com um perito nacional em ICPC-2. Procedeu-se a uma análise descritiva da proporção de respostas correctas, falhas de classificação e principais erros de codificação observados. Comparam-se as respostas dos internos com e sem formação prévia em ICPC-2.

Resultados: A taxa de resposta foi de $47,0 \%$. Foram classificados correctamente $56,5 \%$ dos motivos de consulta, $75,9 \%$ dos problemas e $48,8 \%$ dos procedimentos. Verificou-se que os internos codificaram frequentemente em excesso situações abordadas na consulta que não constituem motivos segundo a definição da ICPC-2; omitiram frequentemente o código «medicina preventiva/manutenção da saúde» dos problemas e motivos de consulta; e, nos procedimentos, raramente foram codificados os exames médicos completo ou parcial realizados na consulta. Os internos que fizeram formação codificaram correctamente mais motivos de consulta $(72,3 \%$ vs $55,1 \%)$ e problemas $(85,0 \%$ vs $74,8 \%)$.

Conclusões: Os internos parecem ser melhores na codificação de problemas do que nos motivos de consulta ou procedimentos. São frequentes erros relacionados com a codificação de actividades preventivas e o exame médico. Os internos que fizeram formação específica na utilização da ICPC-2 tiveram melhores resultados na codificação de motivos de consulta e problemas.

Palavras-chave: Classificação; Medicina Familiar; Internato Médico.

\section{INTRODUÇÃO}

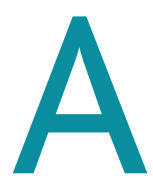

Classificação Internacional de Cuidados Primários (ICPC - no original em inglês, International Classification of Primary Care) foi desenvolvida pelo comité de classificações da Organização Mundial de Médicos de Família (WONCA) como uma classificação própria para utilização nos

*Assistente Eventual de Medicina Geral e Familiar - USF São Julião - ACES Oeiras. Assistente Convidado Voluntário - Departamento de Medicina Geral e Familiar Faculdade de Ciências Médicas da Universidade Nova de Lisboa.

**Assistente de Medicina Geral e Familiar - USF São Julião - ACES Oeiras. cuidados primários. ${ }^{1,2}$ A ICPC permite classificar motivos de consulta, diagnósticos e procedimentos. ${ }^{1} \mathrm{O}$ motivo de consulta é a razão que leva o indivíduo a procurar os cuidados de saúde. Traduz o ponto de vista do doente e, como tal, não deve ser sujeito à interpretação do médico. Todas as rubricas da classificação podem ser usadas para codificar o motivo de consulta. Os problemas resultam da avaliação do médico e podem ser codificados sinais ou sintomas e/ou diagnósticos, usando os componentes 1 e 7 respectivamente. Uma grande parte das rubricas aqui incluídas contém critérios de 
inclusão e exclusão que auxiliam a codificação. Os procedimentos permitem registar as intervenções realizadas, sejam elas imediatas (como a realização do exame objectivo) ou subsequentes (como o pedido de análises). Podem ser usados para codificar procedimentos os componentes 2, 3, 5 e parte do componente 6 .

Em Portugal, a ICPC-2 é utilizada como padrão dos registos clínicos de Medicina Geral e Familiar (MGF), em investigação e no treino de médicos em medicina familiar. ${ }^{2}$ Durante vários anos a sua utilização na prática dos médicos de família foi limitada, em boa parte devido à utilização de sistemas de registo em papel. ${ }^{2}$ No entanto, com a informatização recente de um número progressivamente maior de centros de saúde, essa situação tem vindo a mudar. Actualmente, todos os sistemas de registo electrónico utilizados nos centros de saúde e nas unidades de saúde familiar permitem e incentivam a utilização da ICPC-2.3.,45 Através destes sistemas electrónicos, a maior parte dos médicos de família portugueses passou a utilizar diariamente a ICPC-2. A implementação da ICPC-2 no sistema electrónico mais utilizado (SAM - Sistema de Apoio ao Médico) foi progressiva e, à data da realização deste trabalho, apenas eram disponibilizados os códigos e os títulos da ICPC-2, sem informação sobre critérios de inclusão e exclusão. Essa informação estava disponível nos restantes sistemas electrónicos (MedicineOne eVitacare). A informação contida nestes registos electrónicos acerca de motivos de consulta, problemas e procedimentos referentes a quase 30 milhões de consultas por ano ${ }^{6}$ é potencialmente uma fonte muito rica para a investigação académica em MGF e planeamento dos serviços de saúde. O estudo destes registos, possibilitado pela existência de um sistema de classificação uniforme, permitirá conhecer em muito maior detalhe a realidade dos cuidados de saúde primários em Portugal, à semelhança do que já é feito noutros países. ${ }^{7}$ Porém, esses estudos ainda não foram feitos e trabalhos muito meritórios, mas porventura já desactualizados, como os trabalhos iniciais que estudaram a aplicação da ICPC em Portugal ${ }^{8,9} \mathrm{e}$ a tese de doutoramento do Professor Guilherme Jordão, ${ }^{10}$ continuam a ser frequentemente citados. Outros trabalhos mais recentes, como o de Rodrigues, ${ }^{11}$ reportam apenas realidades locais.

A ICPC foi desenvolvida sobretudo tendo em vista a sua aplicação em investigação, mas rapidamente mos- trou que poderia ser utilizada na prática clínica diária, sobretudo com o desenvolvimento da ICPC-2., ${ }^{2,12}$ No entanto, quando passa a ser usada fora do ambiente controlado do contexto de investigação, aumenta a variabilidade de classificação entre médicos e entre grupos de médicos, o que pode pôr em causa a precisão dos dados. ${ }^{10}$ Para que as informações contidas nos registos médicos electrónicos possam ser estudadas e comparadas é necessário que os médicos saibam aplicar na prática a ICPC-2 e o façam de forma consistente. O treino dos médicos de família na utilização da ICPC-2 poderá ser uma forma de evitar erros e viéses na utilização da classificação. Se isso não acontecer, as diferenças encontradas poderão ficar a dever-se à variabilidade inter-classificador e não representarem variações reais. Na nossa prática diária encontramos diversos relatos de opinião sugerindo que a formação dos médicos internos de MGF nesta área poderá ser insuficiente. No entanto, não existem estudos recentes que avaliem a capacidade de internos portugueses para codificar com a ICPC-2. Assim, este trabalho teve por objectivo determinar a capacidade de médicos na segunda metade do internato de MGF em Portugal para codificar com a ICPC-2.

\section{MÉTODOS}

Foi feito um estudo transversal, analítico, cuja colheita de dados ocorreu entre 11 e 31 de Julho de 2008. Considerámos como universo os médicos a frequentar o internato médico da área de MGF cuja formação teórica foi da responsabilidade da Coordenação de Internato de MGF da Zona Sul (CIMGF Sul), que inclui as regiões de Lisboa e Vale do Tejo, Ribatejo, Alentejo e Algarve. Os internos dos Açores e Madeira, apesar de terem Coordenações de Internato próprias, fizeram a formação curricular teórica em conjunto com os internos da CIMGF Sul, pelo que também foram incluídos. Definimos como internos que já deveriam ter adquirido competências na utilização da ICPC-2 aqueles que se encontravam a frequentar a segunda metade do internato (tinham pelo menos 18 meses de formação). Destes, foi seleccionada uma amostra de conveniência composta por cem médicos internos dos 29. (início da formação em MGF em Março de 2006) e $30 .^{\circ}$ (início da formação em Janeiro de 2007) cursos da CIMGF Sul, cujos endereços de correio electrónico eram conheci- 
dos dos autores.

Os participantes foram contactados por correio electrónico, sendo-lhes endereçado um convite em que os objectivos do estudo eram explicados e lhes era pedido que codificassem com a ICPC-2 as descrições de três consultas elaboradas pelos autores. Em cada uma deveriam ser codificados os motivos de consulta, os problemas e os procedimentos efectuados. Os internos deveriam ainda indicar se alguma vez tinham feito formação sobre a ICPC-2 e, em caso afirmativo, qual a formação feita. Era também expressamente pedido que não consultassem ou pedissem ajuda a outros colegas para fazer a codificação, nem partilhassem as suas respostas com outros participantes. As respostas deveriam ser enviadas para um dos autores por correio electrónico. Caso não pretendessem participar no estudo, deveriam indicá-lo aos autores, não sendo pedida qualquer justificação. Se não fosse obtida resposta no prazo definido, era feita uma nova tentativa com o envio de uma segunda mensagem solicitando a participação. O interno era considerado não respondente se voltasse a não responder aos autores.

Foram elaboradas pelos autores descrições de três consultas-tipo de MGF, com o objectivo de permitir avaliar as competências na utilização da ICPC-2 (em anexo). A primeira descrevia uma consulta de saúde do adulto (consulta 1), a segunda de saúde infantil (consulta 2) e a terceira de rastreio oncológico (consulta 3). Estas incluíam a transcrição resumida do diálogo entre médico e utente ao longo da consulta, de forma a possibilitar a codificação do motivo de consulta de acordo com as palavras do doente, e o registo da consulta feito pelo médico em formato SOAP. A codificação padrão dos motivos de consulta, problemas e procedimentos foi determinada pelos autores em colaboração com um perito nacional em ICPC-2. As descrições das consultas foram depois reanalisadas pelos autores e pelo perito em ICPC-2 à luz da codificação definida, clarificando o texto sempre que este poderia ser alvo de mais que uma interpretação. As três consultas continham 13 motivos de consulta, 12 problemas e 15 procedimentos. Durante a análise das respostas foi necessário anular um dos procedimentos que se referia a rastreio do cancro do cólon, por não ser claro na descrição do caso se este era feito através de pesquisa de sangue oculto nas fezes ou colonoscopia/rectosigmoidoscopia.
As respostas foram introduzidas no programa Microsoft Excel (Microsoft 2003) e analisadas de forma descritiva quanto a: proporção de respostas correctas, número de códigos errados e número de codificações em excesso. A análise foi feita separadamente para motivos de consulta, problemas e procedimentos. Definiram-se como respostas correctas os códigos da ICPC-2 submetidos pelos participantes que coincidiam com o padrão previamente definido pelos autores. Os restantes códigos submetidos pelos participantes foram divididos pelos autores em errados e em excesso. Consideraram-se códigos errados os que procuravam classificar um motivo de consulta, problema ou procedimento previamente definido pelos autores, mas que não estavam de acordo com as soluções definidas. Os códigos que não correspondiam a um motivo de consulta, problema ou procedimento descrito no caso e que não podiam ser interpretados como uma tentativa errada para codificar um destes foram considerados em excesso. Consideraram-se falhas de classificação os códigos submetidos em excesso, errados e as omissões (motivo de consulta, problema ou procedimento ao qual não foi atribuído um código correcto ou errado).

\section{Análise estatística}

Os respondentes e não respondentes foram comparados quanto a sexo e curso através do teste exacto de Fisher, usando o software QuickCalcs (GraphPad Software 2005) ${ }^{13}$ e um nível de significância de 0,05.

Procedeu-se ainda a uma análise descritiva dos erros de codificação mais frequentes e à comparação dos internos que afirmaram já ter feito alguma formação sobre ICPC-2 com aquelas dos que responderam nunca ter feito formação.

\section{RESULTADOS}

Dos 100 internos contactados, 45 não responderam às mensagens de correio electrónico, cinco recusaram-se a participar e três emails não foram entregues na caixa de correio do destinatário. Assim, a taxa de resposta foi de $47,0 \%$. A maioria dos participantes era do sexo feminino $(71,7 \%)$ e do $30 .^{\circ}$ curso da CIMGF Sul $(53,2 \%)$. Não se encontraram diferenças entre respondentes e não respondentes quanto ao sexo $(\mathrm{p}=0,667)$. $\mathrm{O}$ mesmo já não se verificou quanto ao curso de origem, com os internos do $30 .^{\circ}$ curso a terem uma maior taxa de res- 
pondentes em relação aos do $29 .^{\circ}$ curso $(59,5 \%$ vs $37,9 \%, \mathrm{p}=0,043)$.

Cinco internos $(10,6 \%)$ assinalaram ter feito formação prévia na utilização da ICPC-2. Três referiram ter feito um curso de ICPC-2 através da Coordenação de Internato de MGF da Região Autónoma da Madeira e dois assistido a um workshop no $24 .{ }^{\circ}$ Encontro Nacional de Clínica Geral. Dois outros internos consideraram como formação o curso curricular "A consulta», feito a todos os internos da CIMGF Sul. No entanto, uma vez que todos os internos da amostra tinham realizado este curso obrigatório (e portanto estavam em condições de igualdade) e o curso não visa o treino com a ICPC-2, optámos por agrupar os resultados destes dois internos com os daqueles que consideraram nunca ter feito formação.

Em média, foram classificados correctamente 56,5\% dos motivos de consulta, 75,9\% dos problemas e $48,8 \%$ dos procedimentos (Quadro I). Por cada consulta, os participantes falharam, em média, 0,99 motivos de consulta, 0,30 problemas e 1,80 procedimentos e apresentaram 0,73 motivos de consulta, 0,17 problemas e 0,49 procedimentos a mais. A maioria dos códigos não codificados correctamente, foram-no por erro e não por omissão (Quadro I).

O Quadro II mostra a proporção média de codificações correctas para cada um dos itens. Uma das falhas mais frequentes é a omissão do código «medicina preventiva/manutenção da saúde» (A98) dos problemas e motivos de consulta. Este problema foi codificado correctamente por $19,6 \%$ dos internos numa consulta de saúde infantil e 13,0\% numa de rastreio do cancro do colo do útero. Na consulta de saúde infantil o código «medicina preventiva/manutenção da saúde» (A98) deveria ter sido usado para classificar um dos motivos de consulta apresentados, mas apenas foi assinalado por $17,4 \%$ dos internos. Outra falha é a não codificação do exame médico completo (-30) ou parcial (-31) nos procedimentos: $13,0 \%$ e $6,5 \%$ dos internos fizeram-no na primeira e segunda consultas, respectivamente, enquanto quase metade $(47,8 \%)$ fê-lo na consulta de saúde infantil. Alguns procedimentos como a educação para a saúde (-45) e a prescrição de medicamentos (-50) apresentam também taxas de codificação baixas, contrastando com o pedido de exames complementa- res de diagnóstico e a citologia do colo do útero, codificados pela maioria dos internos. Os internos codificam em excesso situações que não constituem motivos de consulta segundo a definição da ICPC-2 (Quadro III). Nos casos 1 e 3, os internos consideraram como motivos de consulta os problemas sociais que tinham sido evocados pelo médico e não pelo utente durante a fase inicial da consulta. No entanto, estes constituem apenas $27,7 \%$ do total de motivos de consulta a mais. Os restantes $72,3 \%$ encontram-se dispersos por 36 códigos diferentes, sem que seja possível perceber um padrão comum às três consultas.

Quando os resultados são analisados separando os internos entre aqueles que tiveram ou não formação prévia sobre a utilização da ICPC-2, encontram-se diferenças entre os grupos (Quadro IV). Os internos que fizeram formação codificam correctamente uma maior proporção de motivos de consulta $(72,3 \%$ v $55,1 \%) \mathrm{e}$ problemas $(85,0 \%$ vs 74,8$)$. Apresentam um número menor de motivos de consulta errados $(1,80$ vs 3,12$)$, mas mais do dobro de procedimentos em excesso $(3,20$ vs 1,26). Globalmente, verifica-se uma tendência para os internos que fizeram formação terem uma maior proporção de respostas correctas, menor número de respostas erradas e maior número de codificações em excesso.

\section{DISCUSSÃO}

O nosso trabalho permitiu avaliar a utilização da ICPC-2 por parte dos médicos internos de MGF na segunda metade da sua formação como especialistas. Os resultados obtidos mostraram que os internos não codificaram correctamente uma parte importante das consultas que lhes foram enviadas. Quase um quarto dos problemas não foram codificados correctamente, propor- 
ção que foi maior nos motivos de consulta e ultrapassou os $50 \%$ nos procedimentos. Por conseguinte, os in- ternos parecem ser melhores a codificar os problemas que os motivos ou procedimentos. Estes resultados po-

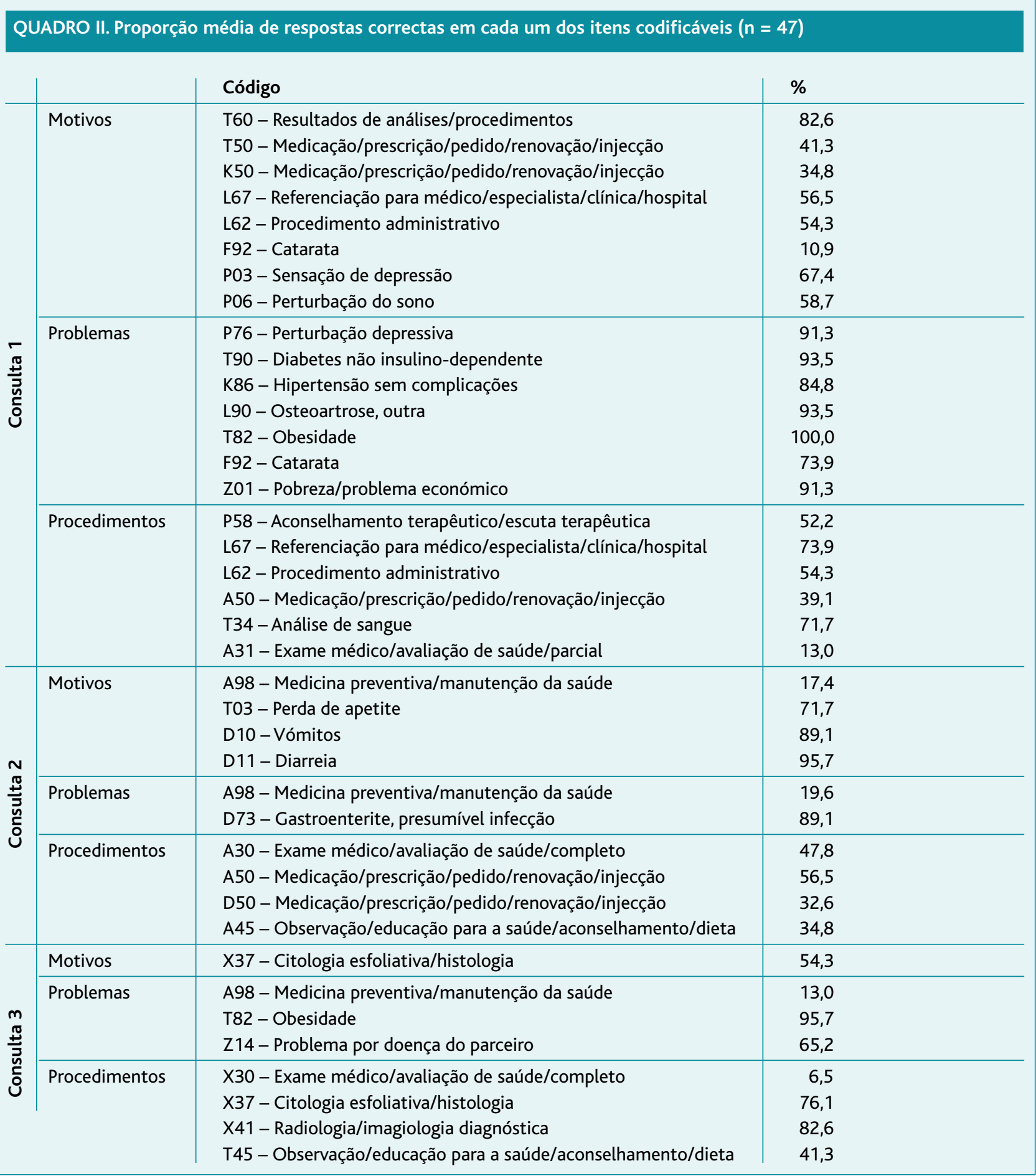




\section{QUADRO III. Codificações em excesso}

\begin{tabular}{|c|c|c|c|}
\hline & & Código & $\mathbf{n}$ \\
\hline \multirow{6}{*}{ 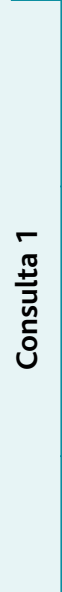 } & Motivos & $\begin{array}{l}\text { Z01 - Pobreza/problema económico } \\
\text { A63 - Consulta de seguimento não especificada } \\
\text { L28 - Limitação funcional/incapacidade }\end{array}$ & $\begin{array}{l}18 \\
5 \\
5\end{array}$ \\
\hline & & Total & 70 \\
\hline & Problemas & $\begin{array}{l}\text { K85 - Tensão arterial elevada } \\
\text { L28 - Limitação funcional/incapacidade } \\
\text { P03 - Sensação de depressão } \\
\text { P06 - Perturbação do sono } \\
\text { T07 - Aumento de peso }\end{array}$ & $\begin{array}{l}3 \\
2 \\
2 \\
2 \\
2\end{array}$ \\
\hline & & Total & 16 \\
\hline & Procedimentos & $\begin{array}{l}\text { A46 - Consulta com prestador de CSP } \\
\text { P46 - Consulta com prestador de CSP }\end{array}$ & $\begin{array}{l}4 \\
3\end{array}$ \\
\hline & & Total & 23 \\
\hline \multirow{5}{*}{$\begin{array}{l}N \\
\stackrel{3}{5} \\
\frac{1}{5} \\
0 \\
0\end{array}$} & Motivos & $\begin{array}{l}\text { A30 - Exame médico / avaliação de saúde / completo } \\
\text { A63 - Consulta de seguimento não especificada }\end{array}$ & $\begin{array}{l}2 \\
2\end{array}$ \\
\hline & & Total & 4 \\
\hline & Problemas & Total & 0 \\
\hline & Procedimentos & $\begin{array}{l}\text { A46 - Consulta com prestador de CSP } \\
\text { A63 - Consulta de seguimento não especificada } \\
\text { A62 - Procedimento administrativo }\end{array}$ & $\begin{array}{l}8 \\
5 \\
3\end{array}$ \\
\hline & & Total & 30 \\
\hline \multirow{6}{*}{ 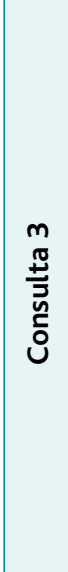 } & Motivos & $\begin{array}{l}\text { Z14 - Problema por doença do parceiro } \\
\text { P01 - Sensação de ansiedade/nervosismo/tensão } \\
\text { X31 - Exame médico/avaliação de saúde/parcial }\end{array}$ & $\begin{array}{l}11 \\
3 \\
3\end{array}$ \\
\hline & & Total & 31 \\
\hline & Problemas & $\begin{array}{l}\text { T07 - Aumento de peso } \\
\text { P02 - Reacção aguda ao stress } \\
\text { T02 - Apetite excessivo }\end{array}$ & $\begin{array}{l}3 \\
2 \\
2\end{array}$ \\
\hline & & Total & 11 \\
\hline & Procedimentos & $\begin{array}{l}\text { K31 - Exame médico/avaliação de saúde/parcial } \\
\text { T31 - Exame médico/avaliação de saúde/parcial } \\
\text { A31 - Exame médico/avaliação de saúde/parcial } \\
\text { A46 - Consulta com prestador de CSP }\end{array}$ & $\begin{array}{l}4 \\
3 \\
2 \\
2\end{array}$ \\
\hline & & Total & 16 \\
\hline \multirow{6}{*}{$\underset{⿱ 艹 \pi}{\stackrel{0}{0}}$} & Motivos & $\begin{array}{l}\text { Z01 - Pobreza / problema económico } \\
\text { Z14 - Problema por doença do parceiro } \\
\text { A63 - Consulta de seguimento não especificada }\end{array}$ & $\begin{array}{l}18 \\
11 \\
7\end{array}$ \\
\hline & & Total & 105 \\
\hline & Problemas & $\begin{array}{l}\text { T07 - Aumento de peso } \\
\text { K85 - Tensão arterial elevada } \\
\text { P06 - Perturbação do sono }\end{array}$ & $\begin{array}{l}5 \\
3 \\
3\end{array}$ \\
\hline & & Total & 27 \\
\hline & Procedimentos & $\begin{array}{l}\text { A46 - Consulta com prestador de CSP } \\
\text { A63 - Consulta de seguimento não especificada } \\
\text { A62 - Procedimento administrativo }\end{array}$ & $\begin{array}{l}14 \\
8 \\
5\end{array}$ \\
\hline & & Total & 69 \\
\hline
\end{tabular}




\begin{tabular}{|c|c|c|c|}
\hline \multicolumn{4}{|c|}{$\begin{array}{l}\text { QUADRO IV. Comparação das respostas em função da formação do } \\
\text { interno (valores médios) }\end{array}$} \\
\hline & $\begin{array}{l}\text { Sem } \\
\text { formação } \\
(n=42)\end{array}$ & $\begin{array}{l}\text { Formação } \\
\text { específica } \\
(n=5)\end{array}$ & Diferença* \\
\hline Motivos correctos (\%) & 55,1 & 72,3 & $+17,2$ \\
\hline Motivos errados (n) & 3,1 & 1,8 & $-1,3$ \\
\hline Motivos a mais (n) & 2,1 & 3,6 & $+1,5$ \\
\hline Problemas correctos (\%) & 74,8 & 85,0 & $+10,2$ \\
\hline Problemas errados (n) & 1,0 & 0,6 & $-0,4$ \\
\hline Problemas a mais (n) & 0,6 & 0,2 & $-0,4$ \\
\hline Procedimentos correctos (\%) & 48,1 & 51,4 & $+3,3$ \\
\hline Procedimentos errados (n) & 5,5 & 4,6 & $-0,9$ \\
\hline Procedimentos a mais $(n)$ & 1,3 & 3,2 & $+1,9$ \\
\hline
\end{tabular}

* Com formação específica - sem formação tamente apreendidos. Mesmo durante a formação na especialidade, é mais frequente a codificação de diagnósticos e listas de problemas e poderá haver haver falta de treino na classificação dos motivos e procedimentos. Nos motivos de consulta, as respostas dos internos denotam também que uma das regras fundamentais na classificação - usar a terminologia e respeitar a visão do doente ${ }^{1}$ - foi frequentemente ignorada. Os internos têm tendência a usar a sua interpretação enquanto técnicos acerca do que o utente afirma, o que não é permitido pela ICPC-2. Do lado dos procedimentos, o facto de não existirem critérios de inclusão e exclusão definidos na ICPC-2 poderá dificultar a utilização da classificação, o que está de acordo com os resultados, onde se verifica maior proporção de erros do que omissões. Há ainda um outro factor explicativo que importa considerar. Os internos, na falta de treino específico, aprendem a utilizar a ICPC-2 com os seus orientadores de formação. Estes poderão também ter lacunas na sua capacidade para utilizar a ICPC-2 e serem uma das fontes dos erros dos internos.

As falhas mais frequentes foram a omissão da codificação de actividades preventivas e do exame médico. As actividades preventivas poderão ser desvalorizadas pelos internos por não se enquadrarem na visão tradicional (mas pouco consonante com a Medicina Familiar) de problemas de saúde e, por essa razão, não codificadas. O exame médico foi codificado por poucos internos nas consultas de saúde de adultos e rastreio oncológico que enviámos, mas quase metade o fez na consulta de saúde infantil. Esta discrepância sugere que o exame objectivo foi muito mais valorizado nesta última. De qualquer forma, apesar dos resultados melhores na consulta de saúde infantil, a codificação do exame médico como procedimento foi globalmente muito baixa. É possível que os internos tenham tendência para fazer corresponder os componentes do registo SOAP com a classificação de motivos de consulta, problemas e procedimentos. Assim, o exame médico poderá não ter sido codificado como procedimento porque não é registado no componente $\mathrm{P}$ (plano) do SOAP.

A codificação em excesso de motivos de consulta po- 
derá estar relacionada com as falhas que já apontámos. Os internos aparentemente tendem a juntar aos motivos de consulta aquela que é a agenda do médico, ignorando o facto de não ter sido o doente a apresentar o problema.

Os nossos resultados mostraram existirem diferenças entre os internos que fizeram ou não formação no uso da ICPC-2. Os internos que tinham feito formação codificaram correctamente mais $17,2 \%$ dos motivos de consulta e $10,2 \%$ dos problemas. Houve ainda uma tendência para um maior número de procedimentos codificados correctamente. O número de códigos errados também foi menor nos internos que fizeram formação. Isto sugere existir benefício do treino na utilização da ICPC-2. Por outro lado, os internos que fizeram formação apresentaram mais procedimentos em excesso, o que foi um resultado não esperado. Porém, estes resultados devem ser interpretados com cautela, uma vez que apenas cinco internos tinham efectuado formação, motivo pelo qual não foram realizados testes estatísticos para comparar estas proporções. Um número tão reduzido de internos nestas condições poderá não ser representativo do universo que fez formação, pelo que não podemos excluir que algumas das diferenças encontradas sejam devidas ao acaso. Seria interessante repetir este estudo noutras regiões do país, procurando incluir na amostra um maior número de internos com treino específico na utilização da ICPC-2.

A metodologia aqui descrita poderá ser utilizada no futuro para avaliar os resultados práticos das formações sobre a ICPC-2, sejam elas destinadas a internos ou a especialistas em MGF. Os participantes poderão classificar casos tipo antes e depois da formação, permitindo avaliar o efeito desta sobre a fiabilidade dos classificadores.

O nosso trabalho apresenta algumas limitações importantes. Usámos uma amostra de conveniência, apesar de os nossos 100 contactos serem quase um censo de todos os internos do $29 .^{\circ} \mathrm{e} 30 .^{\circ}$ cursos da CIMGF Sul. Não temos, porém, dados acerca do total de internos em formação nestes cursos por não sabermos quantos interromperam a sua formação (por mudança de especialidade, para outra região do país ou outros motivos). Contudo, apesar da nossa tentativa para abranger quase todos os internos nestes dois cursos, a taxa de resposta obtida foi baixa. Apesar de o $30 .^{\circ}$ curso ter tido uma maior taxa de respondentes que o 29. ${ }^{\circ}$ curso, não nos parece que tal tenha influenciado os resultados, uma vez que as características dos internos de ambos os cursos são semelhantes. Provavelmente responderam apenas os internos mais motivados e é possível que estes sejam também os que são melhores na utilização da ICPC-2. Assim, os resultados do nosso estudo poderão sobreavaliar as capacidades reais dos internos. Outra das limitações do trabalho foi assumirmos que os casos apresentados tinham apenas uma solução possível - o nosso padrão. Porém, a codificação com a ICPC-2 não é matemática e, apesar de termos tentado que a descrição das consultas fosse o menos ambígua possível (através da codificação - recodificação), é possível que algumas das classificações diferentes do nosso padrão não estivessem erradas.

Algumas das nossas opções de classificação são particularmente polémicas, como, no caso um, a não utilização do código Z01 (pobreza/problema económico) como motivo de consulta e a classificação como P03 (sensação de depressão) do «problema dos nervos»e, no caso 2, a utilização do código A45 (observação/educação para a saúde/aconselhamento/dieta). Noutras situações, a redacção dos casos poderá ter dado origem a alguma ambiguidade. Contudo, a interpretação dos resultados não seria exequível se admitíssemos múltiplas hipóteses de resposta. Para além disso, utilizámos apenas três casos, o que não permite avaliar todas as dimensões da ICPC-2. Se tivéssemos enviado casos diferentes, os resultados poderiam ter sido outros. No entanto, não estão definidos modelos de consulta que possam ser usados na avaliação da capacidade para classificar com a ICPC-2. Não temos termo de comparação para os nossos resultados, já que não encontrámos nenhum estudo semelhante a nível nacional ou internacional. Mesmo que esses estudos tivessem sido encontrados, seria difícil fazer a comparação com o nosso por não existir um instrumento de medida padronizado.

A ICPC-2, como qualquer classificação, procura capturar num conjunto limitado de signos uma realidade altamente complexa - a variedade de motivos de consulta, problemas e procedimentos com que o médico de família se depara. Para que a classificação permita uma comunicação sem ruído, é essencial que cada significante tenha o mesmo significado para todos os seus 
utilizadores. Este trabalho sugere que isso não acontecerá com os médicos internos de MGF em Portugal. Apesar de não termos estudado outros grupos, é provável que o mesmo aconteça com os especialistas em MGF. Um dos caminhos possíveis será a definição de consensos nacionais, que poderão definir o que deve ser codificado e quais os códigos a utilizar em certas situações tipo. Outro será aumentar a oferta formativa e o treino na utilização da ICPC-2.

Em conclusão, o nosso estudo mostrou que os internos são mais fiáveis a codificar problemas do que motivos de consulta ou procedimentos; que são frequentes falhas na codificação de actividades preventivas e do exame médico; e que os internos que fizeram formação específica na utilização da ICPC-2 tiveram melhores resultados na codificação de motivos de consulta e problemas. Este trabalho permite conhecer as competências dos internos para classificar com a ICPC2 e os resultados são um alerta para a necessidade de formação nesta área. No futuro, será importante estudar se o treino dos médicos internos na utilização da ICPC-2 melhora a sua capacidade para codificar correctamente e de forma completa as suas consultas.

\section{AGRADECIMENTOS}

Ao Dr. José Mendes Nunes pelo seu apoio na definição da classificação padrão das consultas e sua revisão e pela sua crítica ao manuscrito.

Aos médicos internos dos $29 .^{\circ}$ e $30 .^{\circ}$ cursos da Coordenação de Internato de Medicina Geral e Familiar da Zona Sul pela sua disponibilidade e participação.

\section{REFERÊNCIAS BIBLIOGRÁFICAS}

1. Comissão de Classificações da WONCA, Classificação Internacional de Cuidados Primários. 2a ed. Lisboa: Oxford University Press; 1999.

2. Miller G. ICPC story. WONCA International Classification Committee. 2004Apr 26. Disponível em: http://www.globalfamilydoctor.com/wicc/ icpcstory.html [acedido a 15/10/2008].

3. Boo E. Manual SAM v8.0 - Novas funcionalidades [Internet]. Porto:ARS Norte. 28 Jul 2008. Disponível em: http://portal.arsnorte.minsaude.pt/portal/page/portal/ARSNorte/Documentos/Manuais/SAM\%2 0-\%20Manual\%20v80.pdf [acedido em 15/10/2008].

4. Medicine One na Consulta Médica [Internet]. Ideias sem fim. Disponível em: http://www.medicineone.net/Soluções/MedicineOnePrima-
ryCareHospitalSuite/Naconsultamédica/tabid/130/Default.aspx [acedido em 15/12/2008].

5. Vitacare - Funcionalidades [Internet]. Netvita - Sistemas de Informação. Disponível em: http://www.netvita.com/prod_vitacare_func.asp [acedido em 25/10/2008].

6. Consultas com médicos de família por habitante / ano [Internet]. Indicadores e Metas do Plano Nacional de Saúde. Alto Comissariado da Saúde. 10 Out 2008. Disponível em: http://www.acs.minsaude.pt/pns/pt/sistema-de-saude/consultas-com-medicos-de-familia-por-habitante-ano/ [acedido em 26/10/2008].

7. Britt H, Miller GC, Charles J, Pan Y, Valenti L, Henderson J, et al. General practice activity in Australia 2005-06. General practice series no. 19. AlHW cat. no. GEP 19. Canberra:Australian Institute of Health andWelfare, 2007. Disponível em: http://www.aihw.gov.au/publications/ index.cfm/title/10377 [acedido em 26/10/2008].

8. Luz A, Saraiva JG, Silva FS. The new episodes study 1989-90. In: Lamberts $\mathrm{H}$, Wood M, Hofmans-Okkes I, editors. The International Classification of Primary Care in the European Community. New York, NY: Oxford Medical Press; 1993. p. 111-5.

9. Saraiva JG, Saraiva MN. Two Portuguese GPs at work: description and comparison of their daily routines with ICPC. In: Lamberts H, Wood M, Hofmans-Okkes I, editors. The International Classification of Primary Care in the European Community. New York, NY: Oxford Medical Press; 1993. p. 116-8.

10. Jordão JG. A Medicina geral e familiar: caracterização da prática e sua influência no ensino pré-graduado [tese de doutoramento]. Lisboa: Faculdade de Medicina de Lisboa; 1995.

11. Rodrigues JG. Porque consultam os utentes o seu Médico de Família? Rev Port Clin Geral 2000 Nov-Dez; 16 (6): 442-52.

12. Soler JK, Okkes I, Wood M, Lamberts H. The coming of age of ICPC: celebrating the 21st birthday of the International Classification of Primary Care. FaM Pract 2008 Aug; 25 (4): 312-7.

13. QuickCalcs [Internet]. GraphPad Software 2005. Disponível em: http://www.graphpad.com/quickcalcs/ [acedido em 26/10/2008].

Daniel Pinto é editor da RPCG e não esteve envolvido no processo de revisão editorial do presente artigo. Susana Corte-Real declara não possuir conflitos de interesses.

\section{ENDEREÇO PARA CORRESPONDÊNCIA}

Daniel Pinto

Rua da Fonte, 7 - Tornada

2500-315 Caldas da Rainha

Email: danieljllpinto@gmail.com

Recebido em 26/11/2008

Aceite para publicação em 17/02/2010 


\section{ABSTRACT}

\section{CODING WITH THE INTERNATIONAL CLASSIFICATION OF PRIMARY CARE BY FAMILY MEDICINE RESIDENTS}

Objectives: To determine the ability of Portuguese doctors in the second half of their family medicine residency to code with the International Classification of Primary Care - revised version (ICPC-2).

Study design: Cross-sectional.

Setting: South of mainland Portugal, Azores e Madeira.

Participants: Residents in the 29th and 30th courses of the Family Medicine Residency Coordination of South Portugal.

Methods: A convenience sample of 100 residents was contacted by email, and asked to code three clinical vignettes written by the authors. The correct coding of reasons for encounter, diagnoses, and processes was determined by the authors with the help of a national ICPC-2 expert. We made a descriptive analysis of the proportion of correct answers, failures of classification, and most frequent errors. The answers of residents with and without previous training in ICPC- 2 usage were compared.

Results: The participation rate was $47.0 \% .56 .5 \%$ of reasons for encounter, $75.9 \%$ of diagnoses, and $48.8 \%$ of processes were correctly classified. Residents frequently coded in excess parts of the visit that are not, by the ICPC-2 definition, reasons for encounter; they frequently left out the code "health maintenance/preventive medicine" from problems and reasons for encounter; and, in processes, they seldom code the complete and partial medical examination. Residents who had previous training in ICPC-2 usage correctly coded more reasons for encounter ( $72.3 \%$ vs $55.1 \%$ ) and problems ( $85.0 \%$ vs $74.8 \%$ ).

Conclusion: Residents appear to be better at coding diagnosis than reasons for encounter or processes. Errors in the coding of preventive activities and medical examination are frequent. Residents who had training in ICPC- 2 usage had better results in coding of reasons for encounter and problems.

Keywords: Classification; Family Practice; Residency. 


\section{ANEXO}

\section{CASO 1}

Carlos, 65 anos, diabético tipo 2 e hipertenso. Vem hoje a consulta programada de seguimento. Medicação habitual: Glibenclamida 2,5 mg + Metformina 500mg (2 cp antes do pequeno-almoço e 2 antes do jantar), Ramipril $5 \mathrm{mg}$ + Hidroclorotiazida $25 \mathrm{mg}$ (1 cp ao pequenoalmoço) e Ácido Acetilsalicílico $150 \mathrm{mg}$ (1 cp ao pequeno-almoço).

Médico: Então Sr. Carlos, o que o traz cá hoje?

Carlos: Sr. Doutor, é para mostrar as análises dos diabetes, pedir os medicamentos que já estão todos a terminar, pedir uma credencial para a Ortopedia, para o médico que está a ver o meu joelho. E dizer que fui operado à minha catarata. Ainda ando a colocar os pingos. E preciso também de uma informação médica de incapacidade por causa do joelho.

Médico: E mais, Sr. Carlos?

Carlos: Ai doutor, a minha mulher diz que é para eu lhe falar dos meus nervos.

Médico: Então Sr. Carlos, como se tem sentido, porque é que a sua mulher disse isso?

Carlos: [Choro fácil] Detesto querer fazer as coisas e não poder. O meu joelho incapacita-me e a minha falta de visão não ajuda. Dependo da minha mulher para tudo e, quando ela está a trabalhar e eu preciso de ir ao médico, tenho que pagar a uma senhora para me acompanhar. A minha reforma é uma miséria... O doutor bem me diz para comer frutas e legumes, mas eu até já ando a cortar na comida. Ando triste, não tenho vontade de ver ninguém e desde há duas semanas que tenho dificuldade em dormir.

Médico: Parece-me que está deprimido com toda esta situação.

[...psicoterapia de suporte...]

\section{Exame objectivo:}

Peso: $96,5 \mathrm{~kg}$ (consulta anterior $96 \mathrm{~kg}$ ) IMC $35,4 \mathrm{~kg} / \mathrm{m}^{2}$ TA: $160 / 85 \mathrm{mmHg}$

Análises: $\mathrm{Hb}_{\mathrm{AlC}}-7,3 \%$ (consulta anterior 7,0\%)

Médico: Esta análise que mostra os valores de açúcar dos últimos 3 meses está mais alta que da última vez e a sua tensão também está pior. Gostaria de lhe introduzir mais um medicamento para a tensão, Sr. Carlos. E também considero ser importante iniciar um antidepressivo, para que esteja mais sereno. Concorda? Custam $\mathrm{xx} €$ acha que consegue comprá-los?

Carlos: Sim, Doutor... Esta semana ainda não, que ainda não recebi a pensão. Mas para a semana vem o meu filho visitar-me e eu peço-lhe ajuda.

Médico: Sr. Carlos, tem aqui as receitas já com os novos medicamentos para a tensão e o dos nervos, a análise do açúcar para repetir dentro de 3 meses e a credencial para o Ortopedista. Quanto à informação médica, passe cá amanhã de manhã, pois irei preenchê-la quando terminar as consultas. Marque lá fora consulta para dentro de 2 semanas, para avaliar como se tem sentido.

\section{Registo:}

S: Vem para seguimento, com análises. Pede informação médica para avaliação de incapacidade e credencial para Ortopedia (joelho). Pede renovação de receituário. Realizou cirurgia a catarata OD. Refere dificuldades económicas. Sente-se triste, com tendência ao isolamento e insónia há 2 semanas.

O: Choro fácil, mímica facial empobrecida. Peso: 96,5 $\mathrm{kg}$ (IMC 35,4 kg/m²). TA: 160/85 mmHg. $\mathrm{Hb}_{\mathrm{AlC}}: 7,3 \%$.

A: Depressão.

Diabetes tipo 2 - controlo aceitável.

HTA - mal controlada.

Gonartrose bilateral.

Obesidade.

Catarata - operado.

Dificuldades económicas.

P: Psicoterapia de suporte. Credencial para Ortopedia e passo informação médica para avaliação de incapacidade. Inicia Amlodipina, Sertralina e Alprazolam à noite e em SOS. Mantém restante terapêutica (renovo receituário). Análises $\left(\mathrm{Hb}_{\mathrm{AlC}}\right)$. Próxima consulta dentro de 2 semanas. 


\section{CASO 2}

Tomás, 15 meses, saudável.Vem à consulta de saúde infantil com a mãe, Maria.

Médico: Olá Maria, como tem andado o Tomás?

Maria: Sr. Doutor, hoje trazia o Tomás para a consulta de rotina. Mas há outra coisa que me preocupa: desde ontem que não quer comer nada e esta madrugada começou a vomitar e teve diarreia. Eu tentei dar-lhe o leite hoje de manhã, mas ele vomitou.

Médico: Tem febre? E quantas vezes vomitou, como era a diarreia?

Maria: Não tem febre. Vomitou 3 vezes com esta última e fez uma diarreia muito líquida 2 vezes.

Médico: E a diarreia tinha sangue?

Maria: Ai Doutor, não tinha. Era muito amarela.

Médico: Então vou observar o Tomás como já tinha sido programado e ver se está desidratado ou tem mais alguma alteração no exame.

\section{Exame objectivo:}

Boa vitalidade. Língua húmida. Turgor cutâneo mantido. Peso: 12,0 kg (P75-90). Comprimento: $82 \mathrm{~cm}$ (P7590). PC: $48 \mathrm{~cm}$ (P50-75). Sem sinais meníngeos ou de discrasia hemorrágica.

ACP: Sem outras alterações. Abdómen: livre, indolor. Orofaringe: sem alterações. Otoscopia: sem alterações. Desenvolvimento psicomotor: normal

Médico: Vejo que o Tomás não está desidratado. Vamos dar-lhe um soro de rehidratação oral e ver se ele tolera. Tem que dar uma colher de 5 em 5 minutos.

$[\ldots]$

Médico: Já vi que o Tomás tolerou o soro. Deve dar-lhe chá açucarado em casa e fazer dieta. Vou passar-lhe uma receita de Paracetamol para fazer se ele tiver febre. Volta se os vómitos e a diarreia persistirem e vir que ele está muito prostrado e com a língua seca. [...Cuidados antecipatórios...]. Volta à consulta dentro de 3 meses.

\section{Registo:}

S: Vem para vigilância. Refere anorexia, vómitos (3 episódios), o último dos quais há cerca de 1 hora e diarreia (2 episódios de dejecções líquidas, sem muco ou sangue) desde esta madrugada. Nega febre, tosse ou outras queixas.
O: Boa vitalidade. Língua húmida. Turgor cutâneo mantido. Peso: 13,1 kg (P90-95). Comprimento: 82cm (P7590). PC: $48 \mathrm{~cm}$ (P50-75). Restante exame sem alterações. A: Bom desenvolvimento estaturo-ponderal e psicomotor. Gastroenterite aguda viral.

P: Fez soro de rehidratação oral que tolerou. Cuidados antecipatórios. Reforço da ingestão hídrica e dieta. Paracetamol se febre. Volta se persistência dos vómitos e diarreia, com incapacidade para ingestão de líquidos. Próxima consulta dentro de 3 meses.

\section{CASO 3}

Idalina, 54 anos, casada, com 2 filhos. Vem à consulta de rastreio oncológico para realização de citologia.

Médico: Bom tarde Idalina, o que a traz cá hoje? Idalina: Tal como combinámos, venho para o doutor me fazer a citologia.

Médico: E como tem passado o seu marido?

Idalina: Ai doutor, ando preocupada com ele. Começou os tratamentos de quimioterapia novamente e sou só eu que o tenho acompanhado.

Médico: E como se tem sentido?

Idalina: Espero que os tratamentos resultem, que o meu marido recupere fisicamente e deixe de estar tão em baixo. Por outro lado, gostaria que os meus filhos estivessem mais presentes, para que eu pudesse descansar um pouco e para que o meu marido se sentisse mais apoiado.

Médico: Vejo que não fez a mamografia que lhe tinha pedido há 1 ano. Vou pedir-lhe novo exame e um outro, para rastreio do cancro do intestino.

\section{Exame objectivo:}

Peso: $98 \mathrm{~kg}$ (consulta anterior $95 \mathrm{~kg}$ ) IMC $38,8 \mathrm{~kg} / \mathrm{m}^{2}$

TA: $125 / 85 \mathrm{mmHg}$

Shiller - coloração homogénea.

Exame ginecológico - sem alterações.

Palpação mamária - normal.

Médico: Aumentou 3 quilos no peso. O que aconteceu? Idalina: Sabe Doutor, toda esta situação do meu marido fez com que me vingasse na comida. Durante o dia como muito pouco e à noite ataco o frigorífico e a dispensa.

Médico: Compreendo que toda esta situação seja difí- 
cil, mas a comida não constitui solução. O seu peso continua a aumentar e caso este estado não se altere, a Idalina corre risco de ter graves problemas de saúde. Tem de tentar comer várias vezes durante o dia e fazer caminhadas.

Idalina: Pois é Doutor, qualquer dia não conseguirei ajudar o meu marido e os meus ossos já se queixam. Vou tentar organizar o meu horário para andar um pouco a pé com uma vizinha minha.

Médico: Combinado Idalina. Tem aqui as requisições dos exames de que lhe falei. Depois marque consulta quando tiver os resultados.

\section{Registo:}

S: Vem para citologia. Mantém-se como cuidadora do marido, preocupada com a saúde deste.

O: Peso: 98 kg; IMC = 38,8 kg/m²; TA: 125/85 mmHg

A: Rastreio do cancro do colo do útero e da mama.

Obesidade.

Preocupada com a saúde do companheiro.

P: Citologia. Mamografia. Deve efectuar caminhadas e dieta polifraccionada. Volta com resultado de exames.

\section{PANTOJA ROJÃO}

António Manuel Pantoja Rojão nasceu em Évora, em 1943. Em 1969, licenciou-se em Medicina na Universidade de Coimbra. Actualmente, exerce Medicina em Lisboa. Foi sócio da Sociedade nacional de Belas Artes e membro da Direcção da SOPEAM (1994-1998).

\section{EXPOSIÇÕES INDIVIDUAIS (1989-2008)}

Casa do Alentejo; Galeria de Arte do Hotel Meridien; Sociedade Nacional de Belas Artes; Pousada da Rainha Santa Isabel, Estremoz; Galeria Municipal da Câmara Municipal de Sesimbra; Palácio D. Manuel, Évora; Museu Regional de Sintra; Museu da Água da EPAL; Museu Alberto de Monsaraz; Sede da Ordem dos Médicos; Auto-Clube Médico Português; Galeria Municipal de Mourão; Fundação Alentejo Terra-Mãe; Edifício Central da Câmara Municipal de Lisboa; Casa Municipal da Cultura de Coimbra.

\section{EXPOSIÇÕES COLECTIVAS (1989-2008)}

Participou em mais de 100 exposições colectivas no país e no estrangeiro, das quais se destacam: VII eVIII Congresso Nacional de Medicina, na Fundação Calouste Gulbenkian; Jogos Médicos Nacionais «O Médico na Arte», Tróia; «Salão do Pequeno Formato», Casino do Estorial; Galeria Marabello, Barcelona; Caixa Geral de Depósitos; «Semana do Castelo», Mourão; Bienais do Alentejo; Criativarte, Reguengos de Monsaraz; Recife - Brasil.

\section{REPRESENTAÇÕES}

Encontra-se representado em várias colecções particulares e de entidades públicas e privadas, nomeadamente: Museus de Évora, Sintra, Portimão, Ovar, Guimarães e Museu da Cidade de Lisboa; Câmara Municipal de Évora e Sesimbra; Hotel Meridien; Enatur; Hospital dos Capuchos; Ordem dos Médicos e Federação Nacional dos Médicos.

Editou várias serigrafias no Centro Português de Serigrafia e na Galeria Aparte.

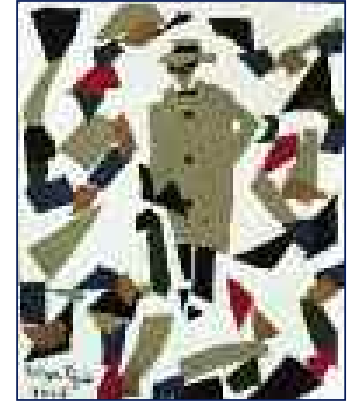

Fernando Pessoa e nós Pantoja Rojão 2006, colagem sobre papel
- «Aspectos das Artes Plásticas em Portugal», 1995, Fernando Infante do Carmo

- «O Mundo Fascinante da Medicina», 1997, do Prof. Armando Moreno

- «Pantoja Rojão», Livro de Artista, 1995 - Edição Pandora

- «Dez Anos de Arte», Retrospectiva da Colecção EPAL, 1998

- «50 Anos de Pintura e Escultura em Portugal», Universitária Editora, 1999

- «Directório de Arte Linhares», 2005/2006

- «Impressões Partilhadas», Centro Português de Serigrafia - 20 Anos a Partilhar a Arte, 2006

- «O Figurativo nas Artes Plásticas em Portugal do Século XXI», 2007, de Afonso Almeida Brandão.

- «Filmografia» - Um filme realizado por Álvaro Queiroz - consta do arquivo da Cinemateca Portuguesa, 2008.

Entre outros escreveram sobre a sua obra, Artur Nobre de Gusmão, Juvenal Esteves, José Luis Porfirio, Margarida Botelho, Edgardo Xavier, Almeida Brandão, Borges Fernandes, João Pinharanda, Rodrigues Vaz, Maria João Fernandes e José de Sousa Machado. 